\title{
Electromyographic Analysis of Upper and Lower Limb Muscles during Gardening Tasks
}

\author{
Sin-Ae Park ${ }^{1}$, A-Young Lee ${ }^{1}$, Jai-Jeong Kim² ${ }^{2}$ Kwan-Suk Lee ${ }^{3}$, Jae-Moo So ${ }^{4}$, and Ki-Cheol Son ${ }^{1 *}$ \\ ${ }^{1}$ Department of Environmental Health Science, Konkuk University, Seoul 143-701, Korea \\ ${ }^{2}$ Department of Physical Education, Graduate School of Konkuk University, Seoul 143-701, Korea \\ ${ }^{3}$ Department of Industrial Engineering, Hongik University, Seoul 121-791, Korea \\ ${ }^{4}$ Department of Physical Education, Konkuk University, Seoul 143-701, Korea
}

\begin{abstract}
Movements of the upper and lower limb muscles during five common gardening tasks were analyzed by using electromyography (EMG). Twenty adults aged in their twenties (mean age, $24.8 \pm 2.4$ years) were recruited. On two separate occasions, subjects visited a garden plot to perform digging, raking, troweling, weeding, and hoeing; all tasks were performed three times with $20 \mathrm{~s}$ intervals for each trial. To measure muscle activation during the five gardening tasks, surface EMG was used. Bipolar surface EMG electrodes were attached to eight upper limb muscles (bilateral anterior deltoid, biceps brachialis, brachioradialis, and flexor carpi ulnaris) or eight lower limb muscles (bilateral vastus lateralis, vastus medialis, biceps femoris, and gastrocnemius) on both sides of the body, for a total of 16 muscles. During the five tasks, photographs were taken of movement phases using a digital video camera. The right flexor carpi ulnaris and brachioradialis showed higher activation than the other upper and lower limb muscles measured during the tasks. All 16 upper and lower limb muscles were actively used only during digging. According to movement analysis of each activity, digging was classified into four movement phases, whereas raking, troweling, weeding, and hoeing each were divided into three movement phases. In each activity, there were high-impact phases in terms of muscle activation; the flexor carpi ulnaris and brachioradialis were identified as major muscles in each impact phase. This analysis may be used to generate biomechanical profiles of gardening tasks for practitioners when designing efficient gardening interventions for physical health or rehabilitation.
\end{abstract}

Additional key words: horticultural activity, horticultural therapy, human issues in horticulture, movement analysis, muscle activation

\section{Introduction}

Gardening has been reported to have therapeutic benefits such as improved health and quality of life, cognitive ability, and socialization (Infantino, 2004; Wang and Macmillan, 2013). Recent research on the physical aspect of gardening indicate that gardening tasks can be classified as low- to high-intensity physical activity for various age groups (Park et al., 2008a, 2011, 2012a, 2012b, 2013a). Common gardening tasks such as digging, raking, transplanting, weeding, watering, and harvesting are considered moderate-to-high intensity for both elementary school students and adults aged in their twenties (Park et al., 2012a, 2013a) and low-to-moderate intensity for older adults (Park et al., 2008a, 2011, 2012b). Park et al. (2009) reported that older gardeners who met physical activity recommendations for health through gardening, e.g., at least $30 \mathrm{~min}$ of moderateintensity physical activity on most days of the week, showed higher overall physical health and hand functional ability (grip strength and pinch force) than older nongardeners. Persons who perform gardening tasks also had fewer chronic diseases and physical functional limitations (Armstrong, 2000; Chen and Janke, 2012). Moreover, weight-bearing gardening motions, such as body movements that work

\footnotetext{
*Comesponding author: kcson@konkuk.ac.kr

※ Received 2 April 2014; Revised 24 April 2014; Accepted 29 April 2014. This paper was supported by the SMART Research Professor Program of Konkuk University.

(C) 2014 Korean Society for Horticultural Science
} 
against gravity and require new bone formulation (Turner and Robling, 2003), can improve muscle strength and bone mineral density (Restuccio, 1992; Turner et al., 2002). Therefore, participation in a gardening program or daily gardening may have the same health benefits as nongardening forms of physical activity.

Gardening tasks also have been used as a treatment to improve physical rehabilitation of individuals with disabilities (Jung, 2005; Kim, 2001; Soderback et al., 2004). Joo et al. (2012) reported that participation in a 22-session horticultural therapy program using hydroponics to cultivate lettuce (Lactuca sativa L.) improved motor performance of developmentally delayed students by increasing fine and gross motor skills.

EMG is an electrical method used to measure the electrical signal produced by skeletal muscle, which results from muscular contraction (De Luca, 1997). Analysis of EMG has been widely used to provide specific information on the functions of agonistic and antagonistic muscles, to detect medical abnormalities, or to biomechanically analyze human or animal movement (Bernardi et al., 1995; Bolgla and Uhl, 2007; De Luca, 1997; van Ingen Schenau et al., 1995). Numerous studies have confirmed the good reliability of EMG in measuring various levels of isometric contraction (Kollmitzer et al., 1999; Lim and Sherwood, 2005; Ochia and Cavanagh, 2007; Yang and Winter, 1983). Moreover, in kinematics and sports biomechanics, various movements of the human body have been biomechanically analyzed in order to improve exercise techniques or apply rehabilitation. For example, walking movement has been divided into two phases-stance and swing-and stance is further classified into five events (event 1, heel strike; event 2, foot flat; event 3, midstance; event 4, heel rise; and event 5, toe-off) (Vaughan et al., 1992).

In previous studies on human issues in the horticulture field, activation of specific upper limb and hand muscles during 15 common indoor horticultural activities performed while sitting at a table was measured using EMG to develop research-based horticultural therapy programs for improving physical health or rehabilitation (Park et al., 2013b). EMG analysis of flower arranging, including cutting, bending, fixing, and winding, also was conducted to develop a horticultural therapy program for physical rehabilitation and applied to stroke patients (Lee et al., 2012).

However, not many studies have kinematically and biomechanically analyzed the movements of human body during various gardening activities for determining mechanisms of how various gardening tasks affect the human body or contribute to health benefits. Therefore, the objective of this study was to conduct movement and activation analysis of the upper and lower limb muscles during five common gardening tasks by using EMG. EMG data can provide quantitative information regarding the activation of muscles. This could be useful in developing an efficient gardening intervention for physical health or rehabilitation.

\section{Materials and Methods}

\section{Subjects}

Twenty male adults aged in their twenties (mean age, $24.8 \pm 2.4$ years) were recruited from Konkuk University in Seoul, South Korea, by phone or word of mouth. Requirements of participation included age in their twenties, no physical activity for $24 \mathrm{~h}$ prior to testing, and access to proper clothing and shoes for gardening (Park et al., 2013b). All subjects were right handed. A description of the study was given verbally to the subjects, and the test schedule for each subject was decided by phone. The subjects were offered US $\$ 10$ as an incentive to complete the test.

Before starting the first test, descriptive information for each subject, such as height and body composition [weight $(\mathrm{kg})$, percent fat, fat $(\mathrm{kg})$, lean $(\mathrm{kg})]$, were measured with an anthropometer (model ok7979; Samhwa, Seoul, South Korea) and body fat analyzer (ioi 353; Jawon Medical, Gyeongsan, South Korea), respectively (Table 1). Body mass index (BMI) was calculated with the following formula [body mass index $=$ weight $(\mathrm{kg}) /$ height $\left.(\mathrm{m})^{2}\right]$.

\section{Experimental Procedures}

Subjects conducted five gardening tasks (digging, raking,

Table 1. Characteristics of the study subjects $(\mathrm{N}=20)$ recruited to analyze movements of the upper and lower limb muscles during five common gardening tasks by using electromyography.

\begin{tabular}{lrc}
\hline Variable & Mean & SD \\
\hline Age (years) & 24.8 & 2.4 \\
Height $(\mathrm{cm})$ & 175.4 & 4.9 \\
weight $(\mathrm{kg})$ & 71.8 & 5.9 \\
Body composition ${ }^{\mathrm{z}}$ & & \\
$\quad$ Fat (kg) & 137.7 & 39.1 \\
$\quad$ Lean (kg) & 580.0 & 41.1 \\
Percent fat (\%) & 19.0 & 4.5 \\
$\quad$ Body mass index $\left(\mathrm{kg} \cdot \mathrm{m}^{-2}\right)$ & 23.3 & 1.8 \\
\hline
\end{tabular}

${ }^{\mathrm{z}}$ Measured using a body fat analyzer (ioi 353; Jawon Medical, Gyeongsan, South Korea). 
Table 2. Descriptions of the five gardening tasks and phases performed by the study subjects to analyze activation of 16 upper and lower limb muscles during five common gardening tasks by using electromyography.

\begin{tabular}{|c|c|}
\hline Gardening task & Description \\
\hline Digging & $\begin{array}{l}\text { Hold the handle of the shovel }(1.3 \mathrm{~kg}) \text { with both hands and plunge about two-thirds of the blade into } \\
\text { the soil using the right foot. Dig and heap the soil to the left side by holding onto the handle with the } \\
\text { right hand and the middle of the stick with the left hand. }\end{array}$ \\
\hline Raking & $\begin{array}{l}\text { Hold on to the rake }(0.9 \mathrm{~kg}) \text { by placing the right hand on the end of the stick and the left hand about } \\
\text { one-third from the end of the stick. Reach out as far as possible with the rake as you lunge forward } \\
\text { with the left leg. Then, strike the rake on the ground. Rake the soil toward the body. }\end{array}$ \\
\hline Weeding & $\begin{array}{l}\text { Squat down (bending the left leg vertically and the right leg horizontally). Grab the weeds with the right } \\
\text { hand, and pull them out by pulling them toward the body. }\end{array}$ \\
\hline Hoeing & $\begin{array}{l}\text { Squat down (bending the left leg vertically and the right leg horizontally). Hold the hand hoe }(0.3 \mathrm{~kg}) \\
\text { with the right hand and lift it to shoulder level. Then, strike the hand hoe on the ground. Draw the soil } \\
\text { toward the body. }\end{array}$ \\
\hline
\end{tabular}
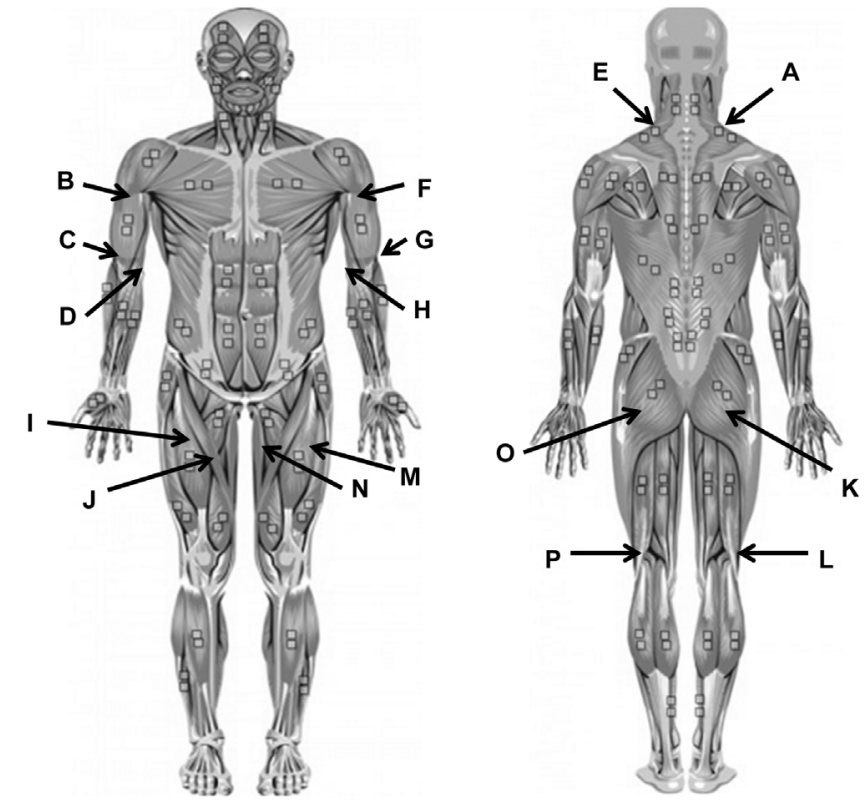

Fig. 1. Upper and lower limb muscles measured by electromyography during five gardening tasks: (A) right anterior deltoid, (B) right biceps brachialis, (C) right brachioradialis, (D) right flexor carpi ulnaris, (E) left anterior deltoid, (F) left biceps brachialis, (G) left brachioradialis, (H) left flexor carpi ulnaris, (I) right vastus lateralis, (J) right vastus medialis, (K) right biceps femoris, (L) right gastrocnemius, (M) left vastus lateralis, (N) left vastus medialis, (O) left biceps femoris, and (P) left gastrocnemius (MyoResearch XP Clinical Edition 1.07 software; Noraxon, Scottsdale, USA).

troweling, hoeing, and weeding) at a garden plot previously prepared at Konkuk University in Seoul, South Korea (Table 2). Subjects visited the garden plot on two occasions to perform each gardening task three times with $20 \mathrm{~s}$ intervals between each trial. The gardening tasks were done in a random order determined by drawing lots. On the first visit, the upper limb muscles were measured, while on the second visit, the lower limb muscles were measured during the five gardening tasks (Fig. 1). Before starting the test, researchers demonstrated how to perform each of the gardening tasks to each subject. All subjects completed the test from May to June 2013, during which time, the average temperature was $26.5 \pm 2.4^{\circ} \mathrm{C}$, and the average humidity was $48.9 \pm 3.8 \%$ at the garden plot (Korea National Weather Service, Seoul, South Korea).

\section{Measurements}

The five gardening activities were recorded using an image analysis video camera (GR-HD1; JVC, Yokohama, Japan). The digital video camera was set at a shooting speed of 60 frames/s with an exposure time of 1/500. In addition, muscle activation level was measured during each activity by using surface EMG (Desktop DTS; Noraxon, Scottsdale, USA) (Fujii and Moritani, 2012; Hawkes et al., 2011; Park et al., 2013b). Biopolar surface EMG electrodes were attached to a total of 16 muscles on both sides of the body during the five gardening tasks (Fig. 1). A trigger and analog digital synchronizer (VSAD-101USB-V2; Visol, Gwangmyeong, South Korea) were used for synchronizing the images and EMG signals.

\section{Data Analysis}

Movement phase analyses of the five gardening activities were performed using video images. For activities in which 
the subjects were videotaped three times, the movement most similar to the description of each activity was used for data analysis. Then, muscle activation was analyzed in each movement phase.

All EMG raw data in this study used MyoResearch XP Master Edition (MyoResearch XP Clinical Edition 1.07; Noraxon, Scottsdale, USA) to process the signals (MyoResearch $X P, 2011)$. First, in order to calculate the average value, maximum value, and integrated EMG (IEMG) value of amplitude, the EMG signal (sampling rate $=1000 \mathrm{~Hz}$ ) was rectified. In addition, a moving average of $10 \mathrm{~ms}$ was used to smoothen the EMG signals, while a finite impulse response bandpass digital filter was used to remove any noise that occurred in the test by cutting off the frequency to a low of $10 \mathrm{~Hz}$ and a high of $250 \mathrm{~Hz}$.

IEMG has been recommended as the most favorable way of describing muscle activation for kinesiologic applications using surface EMG (Morey-Klapsing et al., 2004). The IEMG was calculated by smoothening the maximum isometric movement EMG at a moving average of $10 \mathrm{~ms}$ for each muscle for each subject. Then, the IEMG was set as the maximum voluntary contraction (MVC), the value of which was set as 100 to compare the standardized muscle activation EMG level when each load was warmed up. The peak and average microvolt values for a task of interest were divided by the number of microvolts recorded from the same muscle during maximal effort isometric contraction, and the result was multiplied by 100 to produce a percentage value of MVC (Kasman and Wolf, 2002).

Normalization of EMG data is necessary when electrodes are applied to different muscles and individuals because technical, anatomic, and physiologic factors can affect EMG magnitude (Burden, 2010; Cram and Kasman, 1998). EMG amplitude data can be normalized to the amplitude measured during MVC (Mathiassen et al., 1995). For normalization of EMG data, MVC of selected muscles was measured for each subject. To measure MVC of the brachial muscle, subjects were asked to sit on a bench and lift a fixed object as high as they could using their hands, with their forearms on a support. In order to measure MVC of the biceps muscle, subjects were asked to sit on a bench, with their elbows and torso fixed, and their arms bent at a right angle. Then, subjects were asked to the fixed object towards them using their hands and lower arms. As for MVC of the deltoid muscle, while sitting on a bench, subjects were instructed to fix their back and stretch out their arms at $90^{\circ}$, then pull up the object as much as they could. To measure MVC of the femoral muscle, subjects stretched as much, as they could while sitting on a bench, with their heels fixed and their legs bent at an angle of 70 to $90^{\circ}$. For measuring MVC of the bicephalous femoris muscle, the extent to which subjects could bend their knees at about 20 to $30^{\circ}$ was measured while lying face down on a bench with their buttocks fixed. Finally, MVC of the soleus muscle was measured as the degree to which subjects could lift their heels while sitting on a bench, with their legs at a right angle and the top of their knees fixed. Using a moving average of $10 \mathrm{~ms}$, the EMG data were smoothed, and the maximum value identified was used as the value of the respective muscle. This value then was used as the MVC, which was set at 100 to compare the standardized value of muscle activity during the gardening tasks.

Although normalization of the EMG data was conducted to reduce the noise according to different muscles and individuals, some individuals showed variability in \% MVC IEMG data (e.g., higher SD value than the average value) due to individual characteristics of cellular tissue shape, muscle length, or muscle fatigue (Buchthal, 1957; Hansson et al., 1993; Mathiassen and Winkel, 1990; McGill, 1991; McGill and Norman, 1986). In this study, the variability in IEMG data was also presented in the results (Myers et al., 2005; Page et al., 2003; Stevens et al., 2008).

To conduct a comparative analysis of muscle activity by \% MVC IEMG, a statistical analysis system (SAS version 9 for Windows; SAS Institute, Inc., Cary, NC) was used to carry out Duncan's multiple range test, with the significance level set at $p<0.05$.

\section{Results and Discussion}

In the five gardening activities, EMG activation of the upper limb muscles was higher than that of the lower limb muscles (Tables 3 and 4). This is because gardening tasks were mostly conducted using upper limb muscles, while lower limb muscles played a role in supporting the body. Activation of the right upper limb muscles was relatively higher than that of the left upper limb muscles since all subjects were right handed (Table 3 ).

In all five gardening activities, the right brachioradialis and flexor carpi ulnaris had a higher activation values than any other upper limb muscles (Table 3). Moreover, when digging, troweling, and weeding, the anterior deltoid, and when digging alone, the biceps brachialis showed a statistically significant activation level compared with other right upper limb movements (Table 3). In case of digging alone, four left upper limb muscles were actively used in a statistically significant manner (Table 3). This is because the left hand is also used to hold onto the shovel when digging (Table 2). 
Table 3. Data on maximum activation of eight upper limb muscles during five gardening tasks to analyze movements of the upper and lower limb muscles during five common gardening tasks by using electromyography in right-handed participants.

\begin{tabular}{|c|c|c|c|c|c|c|c|c|c|}
\hline \multirow{3}{*}{$\begin{array}{l}\text { Gardening } \\
\text { task }\end{array}$} & \multicolumn{9}{|c|}{ Maximum voluntary contraction integrated electromyography [mean (SD) $]^{2}$} \\
\hline & \multicolumn{4}{|c|}{ Right $(\%)$} & \multicolumn{4}{|c|}{ Left $(\%)$} & \multirow[b]{2}{*}{$p$} \\
\hline & $\begin{array}{c}\text { Anterior } \\
\text { deltoid }\end{array}$ & $\begin{array}{l}\text { Biceps } \\
\text { brachialis }\end{array}$ & Brachioradialis & $\begin{array}{l}\text { Flexor carpi } \\
\text { radialis }\end{array}$ & $\begin{array}{c}\text { Anterior } \\
\text { deltoid }\end{array}$ & $\begin{array}{c}\text { Biceps } \\
\text { brachialis }\end{array}$ & Brachioradialis & $\begin{array}{l}\text { Flexor carpi } \\
\text { radialis }\end{array}$ & \\
\hline Digging & $31.3(20.5) b c^{y}$ & $25.2(23.1) \mathrm{c}$ & $44.5(32.6) \mathrm{abc}$ & $54.8(49.5) \mathrm{ab}$ & $28.2(29.5) \mathrm{bc}$ & $18.0(15.1) \mathrm{c}$ & $61.5(74.9)$ a & $42.7(36.6) a b c$ & $<0.0001$ \\
\hline Raking & $11.7(11.1) \mathrm{c}$ & $10.5(7.1) \mathrm{c}$ & $33.8(27.0) \mathrm{ab}$ & $40.8(31.3)$ a & $10.7(7.5) \mathrm{c}$ & $12.3(20.8) \mathrm{c}$ & $22.4(28.4) \mathrm{bc}$ & $23.2(13.6) \mathrm{bc}$ & $<0.0001$ \\
\hline Troweling & $34.5(29.0)$ a & $12.3(10.1) \mathrm{b}$ & $46.7(48.3)$ a & $43.4(39.1) \mathrm{a}$ & $5.5(7.2) \mathrm{b}$ & $1.0(1.0) \mathrm{b}$ & $7.9(20.2) \mathrm{b}$ & $10.9(26.7) \mathrm{b}$ & $<0.0001$ \\
\hline Weeding & $26.0(28.6) \mathrm{a}$ & $12.0(9.6) \mathrm{b}$ & $31.5(26.1) \mathrm{a}$ & $31.6(29.6) \mathrm{a}$ & $3.5(1.9) \mathrm{b}$ & $1.6(1.2) \mathrm{b}$ & $4.5(5.9) \mathrm{b}$ & $5.2(4.4) b$ & $<0.0001$ \\
\hline Hoeing & $12.0(8.9) \mathrm{c}$ & $7.3(12.3) \mathrm{cd}$ & $24.4(31.5) \mathrm{b}$ & $38.7(19.0) \mathrm{a}$ & $2.9(2.2) \mathrm{cd}$ & $1.1(1.4) \mathrm{d}$ & $4.0(5.9) \mathrm{cd}$ & $5.4(6.4) \mathrm{cd}$ & $<0.0001$ \\
\hline
\end{tabular}

Table 4. Data on maximum activation of eight lower limb muscles during five gardening tasks to analyze movements of the upper and lower limb muscles during five common gardening tasks by using electromyography in right-handed participants.

\begin{tabular}{|c|c|c|c|c|c|c|c|c|c|}
\hline \multirow{3}{*}{$\begin{array}{l}\text { Gardening } \\
\text { task }\end{array}$} & \multicolumn{9}{|c|}{ Maximum voluntary contraction integrated electromyography [mean (SD)] ${ }^{\mathrm{z}}$} \\
\hline & \multicolumn{4}{|c|}{ Right $(\%)$} & \multicolumn{4}{|c|}{ Left $(\%)$} & \multirow[b]{2}{*}{$p$} \\
\hline & $\begin{array}{l}\text { Vastus } \\
\text { lateralis }\end{array}$ & $\begin{array}{l}\text { Vastus } \\
\text { medialis }\end{array}$ & $\begin{array}{l}\text { Biceps } \\
\text { femoris }\end{array}$ & Gastrocnemius & $\begin{array}{l}\text { Vastus } \\
\text { lateralis }\end{array}$ & $\begin{array}{c}\text { Vastus } \\
\text { medialis }\end{array}$ & $\begin{array}{l}\text { Biceps } \\
\text { femoris }\end{array}$ & Gastrocnemius & \\
\hline Digging & $22.5(16.3)$ & $15.2(25.8)$ & $23.4(25.9)$ & $24.4(26.2)$ & $35.1(26.1)$ & $9.0(6.5)$ & $28.4(34.2)$ & $25.7(25.8)$ & 0.8 \\
\hline Raking & $11.4(13.1)$ & $11.0(16.7)$ & $7.0(4.4)$ & $13.1(22.1)$ & $11.8(6.6)$ & $11.0(10.0)$ & $11.4(8.1)$ & 18.1 (19.4) & 0.5 \\
\hline Troweling & $7.8(17.9) a b c^{y}$ & $1.9(2.9) \mathrm{c}$ & $4.6(3.5) \mathrm{bc}$ & $6.4(12.0) \mathrm{abc}$ & $12.3(10.8) \mathrm{a}$ & $4.2(4.4) \mathrm{bc}$ & $3.9(4.0) \mathrm{bc}$ & $10.7(11.6) \mathrm{ab}$ & $<0.0001$ \\
\hline Weeding & $6.3(11.1)$ & 4.8 (11.2) & $5.6(6.6)$ & 15.0 (26. 9) & $14.6(14.7)$ & $5.8(4.4)$ & $16.1(32.1)$ & $19.4(21.3)$ & 0.2 \\
\hline Hoeing & 7.7 (10.9) & $8.2(20.4)$ & $3.3(3.5)$ & $8.4(10.6)$ & $15.4(18.6)$ & $4.5(3.4)$ & $4.6(4.4)$ & $14.6(23.0)$ & 0.1 \\
\hline
\end{tabular}

${ }^{\mathrm{z}}$ Values are expressed as mean (SD). Means (SD) are expressed as a percentage of the recorded maximum voluntary contraction of each muscle (\% of maximum voluntary contraction integrated electromyography).

${ }^{\mathrm{y}}$ Means with the same letter did not differ significantly according to Duncan's multiple range test, with a significance level of $p<0.05$.

For the lower limb muscles, in all five gardening activities, the left and right gastrocnemius and right vastus medialis were used (Table 4). In addition, in digging alone, the right vastus lateralis and biceps femoris and the left vastus lateralis, vastus medialis, and biceps femoris were actively used in a statistically meaningful manner compared with that during other activities (Table 4). Therefore, while digging, 16 right and left upper and lower limb muscles were actively used (Tables 3 and 4). Park et al. (2011, 2012a, 2012b, 2013a) stated that digging is a high-intensity activity that requires the most energy compared with various other gardening activities. During raking, most of the right and left upper and lower limb muscles were used compared with troweling, weeding, and hoeing, but not as much as those used during digging (Tables 3 and 4). Park et al. (2011, 2012a, 2012b, 2013a) also noted that, of the various gardening activities, raking is the second highest energy consuming and intense activity after digging.
In the five gardening activities, the movement phases were identified, and the muscle activation values in each phase were compared in order to analyze the main muscle and accessory muscle impacts in performing the activity (Tables 5 and 6). Based on the photographs, the movement phases of each gardening task were analyzed by professionals in the field of movement dynamics. Distinguishable movements of each activity were categorized into phases. Accordingly, digging was classified as having four movement phases, while raking, troweling, weeding, and hoeing each were divided into three movement phases (Fig. 2).

For digging, in phases three and four, eight right and left upper limb muscles showed statistically significant activation. In particular, the right and left brachioradialis and flexor carpi ulnaris showed high activation (Table 5). Activation of the lower limbs was very low compared with that of the upper limbs during digging. For the lower limbs, in phases three and four, the right biceps femoris and four 
Table 5. Data on maximum activation of eight upper limb muscles according to each phase of five gardening tasks to analyze movements of the upper and lower limb muscles during five common gardening tasks by using electromyography in right-handed participants.

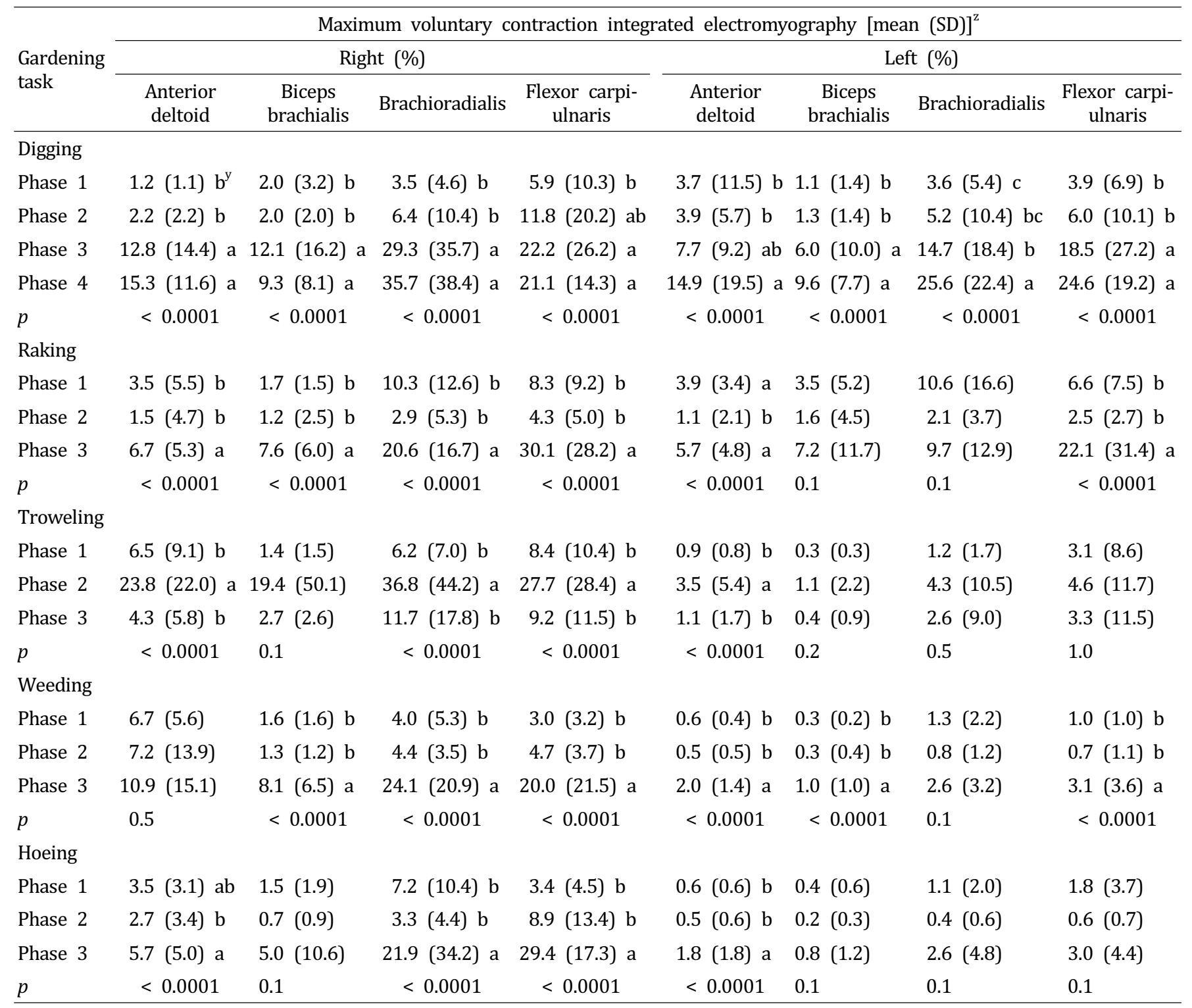

${ }^{\mathrm{z}}$ Values are expressed as mean (SD). Means (SD) are expressed as a percentage of the recorded maximum voluntary contraction of each muscle (\% of maximum voluntary contraction integrated electromyography).

${ }^{\mathrm{y}}$ Means with the same letter did not differ significantly according to Duncan's multiple range test, with a significance level of $p<$ 0.05 .

left muscles, including the vastus lateralis, vastus medialis, biceps femoris, and gastrocnemius, had high activation (Table 6). Therefore, during digging, the phase in which the shovel head is pushed into the soil until the movement of overturning the soil requires the most strength (Fig. 2). The muscles mainly used during this phase were the right and left brachioradialis and flexor carpi ulnaris (Table 5).
During raking, most of the right and left upper limb muscles were used at a statistically significant level during phase three (Table 5). In particular, the right brachioradialis and flexor carpi ulnaris and the left flexor carpi ulnaris had high activation (Table 5). For the lower limbs, although most of the left muscles had a significantly high activation, the lower limb muscles had very low activation compared 
Table 6. Data on maximum activation of eight lower limb muscles according to each phase of five gardening tasks to analyze movements of the upper and lower limb muscles during five common gardening tasks by using electromyography in right-handed participants.

\begin{tabular}{|c|c|c|c|c|c|c|c|c|}
\hline \multirow{3}{*}{$\begin{array}{l}\text { Gardening } \\
\text { task }\end{array}$} & \multicolumn{8}{|c|}{ Maximum voluntary contraction integrated electromyography [mean (SD)] ${ }^{\mathrm{Z}}$} \\
\hline & \multicolumn{4}{|c|}{ Right (\%) } & \multicolumn{4}{|c|}{ Left $(\%)$} \\
\hline & $\begin{array}{l}\text { Vastus } \\
\text { lateralis }\end{array}$ & $\begin{array}{l}\text { Vastus } \\
\text { medialis }\end{array}$ & $\begin{array}{l}\text { Biceps } \\
\text { femoris }\end{array}$ & Gastrocnemius & $\begin{array}{l}\text { Vastus } \\
\text { lateralis }\end{array}$ & $\begin{array}{l}\text { Vastus } \\
\text { medialis }\end{array}$ & $\begin{array}{l}\text { Biceps } \\
\text { femoris }\end{array}$ & Gastrocnemius \\
\hline \multicolumn{9}{|l|}{ Digging } \\
\hline Phase 1 & $4.0(4.7)$ & $7.7(11.4)$ & $2.8(2.4) \mathrm{b}^{\mathrm{y}}$ & $5.1(8.9)$ & $4.2(2.7) \mathrm{b}$ & $3.5(5.2)$ & $3.4(2.4) \mathrm{b}$ & $4.5(4.7) \mathrm{b}$ \\
\hline Phase 4 & $7.5(9.7)$ & $8.2(10.7)$ & $8.9(7.8)$ a & $7.6(6.4)$ & $10.9(9.0)$ a & $10.6(11.3)$ & $10.8(9.9)$ a & $11.0(7.6) \mathrm{a}$ \\
\hline$p$ & 0.1 & 0.6 & $<0.0001$ & 0.8 & $<0.0001$ & 0.1 & $<0.0001$ & $<0.0001$ \\
\hline \multicolumn{9}{|l|}{ Raking } \\
\hline Phase 1 & $3.2(3.5)$ & $3.5(8.4)$ & $2.5(2.9) \mathrm{a}$ & $5.2(12.2)$ & $2.4(2.6) \mathrm{b}$ & $2.3(3.0) \mathrm{b}$ & $3.1(2.9) \mathrm{b}$ & $6.1(9.0) a b$ \\
\hline \multicolumn{9}{|l|}{ Troweling } \\
\hline Phase 1 & $6.0(16.5)$ & $2.4(4.8)$ & $1.5(1.8) a b$ & $3.2(8.1)$ & $3.9(5.3)$ & $4.9(7.1)$ & $1.3(1.8) a b$ & $2.5(2.0) \mathrm{b}$ \\
\hline Phase 2 & $5.0(9.2)$ & $3.4(4.8)$ & $2.9(3.1) \mathrm{a}$ & $6.1(10.6)$ & $7.2(8.4)$ & $9.4(11.9)$ & $2.4(2.3) \mathrm{a}$ & $7.5(5.2) a$ \\
\hline Phase 3 & $2.5(5.6)$ & $1.8(4.4)$ & $1.1(1.2) \mathrm{b}$ & $1.3(1.8)$ & $2.5(3.2)$ & $3.0(5.1)$ & $0.9(1.2) \mathrm{b}$ & $2.8(3.6) \mathrm{b}$ \\
\hline$p$ & 0.6 & 0.5 & $<0.0001$ & 0.2 & 0.1 & 0.1 & $<0.0001$ & $<0.0001$ \\
\hline \multicolumn{9}{|l|}{ Weeding } \\
\hline Phase 1 & $1.7(2.8)$ & $1.2(0.9)$ & $0.8(0.7) \mathrm{b}$ & $1.8(2.6)$ & $4.9(5.5)$ & $5.2(4.5)$ & $1.7(2.3)$ & $4.4(5.3)$ \\
\hline Phase 2 & $1.7(4.3)$ & $1.7(3.3)$ & $0.5(0.5) \mathrm{b}$ & $1.2(1.3)$ & $4.2(7.8)$ & $6.4(9.0)$ & $1.0(0.6)$ & $4.4(4.0)$ \\
\hline$p$ & 0.2 & 0.1 & $<0.0001$ & $<0.0001$ & $<0.0001$ & 0.1 & 0.1 & $<0.0001$ \\
\hline
\end{tabular}

${ }^{\mathrm{z}}$ Values are expressed as mean (SD). Means (SD) are expressed as a percentage of the recorded maximum voluntary contraction of each muscle (\% of maximum voluntary contraction integrated electromyography).

${ }^{\mathrm{y}}$ Means with the same letter did not differ significantly according to Duncan's multiple range test, with a significance level of $p<$ 0.05 .

with the upper limb muscles (Table 6). Therefore, during raking, pulling the soil toward the body required the most strength (Fig. 2). The muscles mainly used during this phase were the right brachioradialis and flexor carpi ulnaris and the left flexor carpi ulnaris (Table 5).

During the phase two of troweling, four upper limb muscles, including the vastus lateralis, vastus medialis, biceps femoris, and gastrocnemius, were actively used with a significantly high activation compared with that in other phases (Table 5). During troweling, plunging the trowel blade into the soil and digging the soil required the most strength (Fig. 2). Since this was performed in a squatting position, the lower limb muscles had very low activation (Tables 5 and 6). For the lower limbs, muscle activation 
was also the highest in phase two (Table 6).

During weeding, the upper limb right and left muscles were used mostly in phase three compared with that in other phases. In particular, activation was the highest for the right brachioradialis and flexor carpi ulnaris. During weeding, stretching out the hand and grabbing and pulling out the weeds required the most strength (Fig. 2). Since the activity was performed while squatting, activation of the lower limb muscles was much smaller than that of the upper limb muscles. For the lower limbs, muscle activation was the highest in phase three (Table 6).

During phases one and three of hoeing, most of the muscles were used in a statistically significant manner (Table 5). In particular, activation was high for the right brachioradialis and flexor carpi ulnaris in phase three. Digging and pulling the soil toward the body with the rake required the most strength (Fig. 2). Since the activity was performed while squatting, activation of the lower
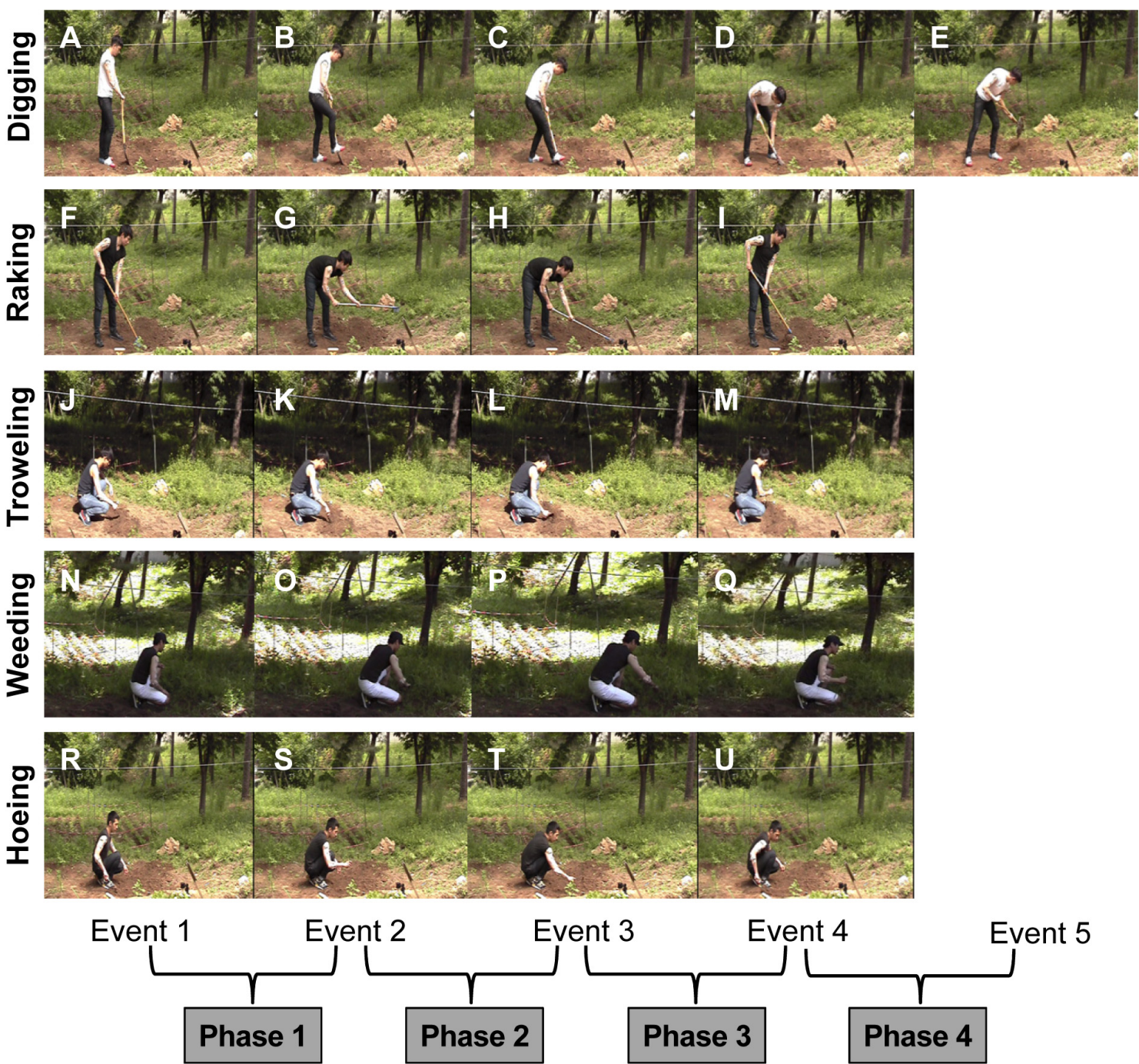

Fig. 2. Movement analysis of five gardening tasks recorded by image photography (GR-HD1; JVC, Yokohama, Japan): (A-E) Events 1-5 of digging: (A) preparation action, (B) put right foot on the shovel, (C) dig a spot, (D) hold the shovel with both hands, and (E) throw away the soil to the left side. (F-I) Events 1-4 of raking: (F) preparation action, (G) extend the rake, (H) hit a spot in the garden, and (I) draw the soil toward the body. (J-M) Events 1-4 of troweling: (J) preparation action, squat, $(\mathrm{K})$ put the hand trowel on a spot in the garden, (L) scoop up the soil, and (M) throw away the soil to the left side. (N-Q) Events 1-4 of weeding: $(\mathrm{N})$ preparation action, squat, (O) stretch out the right arm to weed, (P) hold the weed before pulling out, and (Q) pull out the weed. (R-U) Events 1-4 of hoeing: (R) preparation, squat, (S) extend the hand hoe, (T) hit a spot on the ground, and $(\mathrm{U})$ draw the soil toward the body. 
limb muscles was much smaller than that of the upper limb muscles. For the lower limbs, muscle activation was the highest in phase three (Table 6).

Finally, the right flexor carpi ulnaris and brachioradialis showed higher activation than the other upper and lower limb muscles measured during the five gardening tasks. All 16 upper and lower limb muscles were actively used only during digging. According to movement analysis of each activity, digging was classified into four movement phases, while raking, troweling, weeding, and hoeing each were divided into three movement phases. In each activity, there were high-impact phases in terms of muscle activation; the flexor carpi ulnaris and brachioradialis were identified as major muscles in each impact phase. This analysis may be used to generate biomechanical profiles of gardening tasks for practitioners when designing efficient gardening interventions for physical health or rehabilitation.

In this study, during the phase three of digging and the phase two of troweling, the right anterior deltoid (12.8 $\pm 14.4 \%$ MVC IEMG, $23.8 \pm 22.0 \%$ MVC IEMG by movement) and the biceps brachii $(12.1 \pm 16.2 \%$ MVC IEMG, $19.4 \pm$ 50.1\% MVC IEMG by movement) were actively used, similar to that in Woo (2013)'s drawing and release phases of archery, during which the right anterior deltoid (31.2 \pm 4.2\% MVC IEMG, $27.7 \pm 1.3 \%$ MVC IEMG by each phase) and biceps brachii $(17.4 \pm 6.4 \%$ MVC IEMG, $22.1 \pm 6.2 \%$ MVC IEMG by each phase) were used. In addition, the two phases were similar to the take-back phase of the cross-forehand movement in tennis, during which the right biceps brachii showed comparable activation $(19.4 \pm 3.0 \%$ MVC IEMG) (Yoon et al., 2006). Moreover, in phases three and four of digging, the phase three of raking, and the phase two of troweling, activation of the right brachioradialis (about 20 to 36\% MVC IEMG) was similar to that in the take-back phase of the cross-forehand movement in tennis $(33.2 \pm 7.3 \%$ MVC IEMG, $30.2 \pm 12.4 \%$ MVC IEMG by each phase) (Yoon et al., 2006). Finally, muscle activation during gardening showed a similar trend to muscle activation in sports movements. This suggests that gardening activities can be used as a physical activity intervention or exercise treatment.

The upper extremities play an important role in many daily activities, including eating, drinking, dressing, grooming, and writing, as well as in various sports and leisure activities (Murphy et al., 2006). Therefore, exercising the upper limb muscles has a positive impact on maintaining and improving the performance of daily activities. In the study by Park et al. (2013b), upper limb muscle activation was measured during various indoor horticultural activities. Their study found that the upper limb and hand muscles, including the upper trapezius, biceps brachialis, flexor carpi ulnaris, flexor carpi radialis, brachioradialis, thenar eminence, and hypothenar eminence, were used; in particular, the upper trapezius, thenar eminence, and hypothenar eminence had significantly high activation. Therefore, gardening activities could be applied to strengthen the upper and lower limb muscles to improve the performance of daily activities.

Furthermore, Lee et al. (2012) investigated muscle activation and range of motion in such motions as cutting, bending, winding, and fixing in flower arrangement tasks by using EMG, and then developed a horticultural therapy program for improving range of motion, grip strength, and overall upper limb function of stroke patients. As a result, the horticultural therapy program using flower arrangement tasks based on EMG and range of motion data showed potential as a physical rehabilitation treatment.

Therapeutic intervention consisting of various gardening activities provides a task-oriented approach so that clients can obtain additional benefits, such as motivation, by participating in the therapy session (Bird, 2004), enjoyment by using living plants (Park et al., 2008b), and improvement of psychologic well-being (Armstrong, 2000).

In conclusion, it was demonstrated that various gardening movements could be analyzed in terms of kinematics and kinetics using the movement phase data of the five gardening activities obtained in this study. Additional work is needed to identify the characteristics of each movement in order to create general posture modeling for each movement. Since there is not enough evidence regarding EMG differences according to age and gender (Anderson et al., 1984; Tsuboi et al., 2013; Vaiman et al., 2004; Youdas et al., 2007; Zeller et al., 2003), further research is needed to investigate the EMG data for various horticultural activities based on age or gender. This analysis may be used to generate biomechanical profiles of gardening tasks for practitioners when designing efficient interventions for physical health or rehabilitation. It would be interesting to apply a customized gardening program based on the degree of difficulty and exercise intensity of various gardening activities according to the client's symptoms and physical abilities. Clinicians may use these findings to more effectively target specific muscle groups when prescribing exercises for clients.

\section{Literature Cited}

Anderson, D.S., M.F. Jackson, D.S. Kropf, and G.L. Soderberg. 1984. Electromyographic analysis of selected muscles during sitting push-ups. Effects of position and sex. Phys. Therapy 
64:24-28.

Armstrong, D. 2000. A survey of community gardens in upstate New York: Implications for health promotion and community development. Health Place 6:319-327.

Bernardi, M., M. Solomonow, J.H. Sanchez, R.V. Baratta, and G. Nguyen. 1995. Motor unit recruitment strategy of knee antagonist muscles in a step-wise, increasing isometric contraction. European J. Appl. Physiol. 70:493-501.

Bird, W. 2004. Natural fit: Can green space and biodiversity increase levels of physical activity? Royal Soc. Protection Birds, London, UK.

Bolgla, L.A. and T.L. Uhl. 2007. Reliability of electromyographic normalization methods for evaluating the hip musculature. J. Electromyography Kinesiology 17:102-111.

Buchthal, F. 1957. An introduction to electromyography. Gyldendal, Copenhagen, DK.

Burden, A. 2010. How should we normalize electromyograms obtained from healthy participants? What we have learned from over 25 years of research? J. Electromyography Kinesiology 20:1023-1035.

Chen, T.Y. and M.C. Janke. 2012. Gardening as a potential activity to reduce falls in older adults. J. Aging Phys. Activity 20:15-31.

Cram, J.R. and G.S. Kasman. 1998. The basics of surface electromyography: Introduction to surface electromyography. Aspen Publishers, Inc., Gaithersburg, MD.

De Luca, C.J. 1997. The use of surface electromyography in biomechanics. J. Appl. biomechanics 13:135-163.

Fujii, S. and T. Moritani. 2012. Rise rate and timing variability of surface electromyographic activity during rhythmic drumming movements in the world's fastest drummer. J. Electromyography Kinesiology 22:60-66.

Hawkes, D.H., O. Alizadehkhaiyat, A.C. Fisher, G.J. Kemp, M.M. Roebuck, and S.P. Frostick. 2011. Normal shoulder muscular activation and co-ordination during a shoulder elevation task based on activities of daily living: An electromyographic study. J. Orthopedic Res. 30:53-60.

Hansson, G.A., U. Stromgberg, B. Larsson, K. Ohlsson, I. Balogh, and U. Moritz. 1993. Electromyographic fatigue in neck/shoulder muscles and endurance in women with repetitive work. Ergonomics 35:1341-1352.

Infantino, M. 2004. Gardening: A strategy for health promotion in older women. J. New York State Nurses' Assn. 35(2):10-17.

Joo, B.S., S.A. Park, and K.C. Son. 2012. Improving work adjustment skills in students with mental retardation using hydroponics program. Kor. J. Hort. Sci. Technol. 30:586-595.

Jung, S.A. 2005. Effect of the application of horticultural therapy program by phases of psychological adaptation on the psychosomatic rehabilitation in stroke patients. MS Thesis, Konkuk Univ., Seoul.

Kasman, G.S. and S.L. Wolf. 2002. Surface EMG made easy: A beginner's guide for rehabilitation clinicians. Noraxon INC, Scottsdale, AZ.
Kim, S.Y. 2001. Effect of horticultural therapy on the functional rehabilitation in hemiplegic patients after stroke. MS Thesis, Konkuk Univ., Seoul, Korea.

Kollmitzer, J., G.R. Ebenbichler, and A. Kopf. 1999. Reliability of surface electromyographic measurements. Clinical Neurophysiology 110:725-734.

Lee, S.S., S.A. Park, O.Y. Kwon, J.E. Song, and K.C. Son. 2012. Measuring range of motion and muscle activation of flower arrangement tasks and application for improving upper limb function. Kor. J. Hort. Sci. Technol. 30:449-462.

Lim, H.K. and A.M. Sherwood. 2005. Reliability of surface electromyographic measurements from subjects with spinal cord injury during voluntary motor tasks. J. Rehabilitation Res. Dev. 42:413-422.

Mathiassen, S.E. and J. Winkel. 1990. Electromyographic activity in the shoulder-neck region according to arm position and glenohumeral torque. European J. Appl. Physiol. 61:370-379.

Mathiassen, S.E., J. Winkel, and G.M. Hagg. 1995. Normalization of surface EMG amplitude from the upper trapezius in ergonomic studies - A review. J. Electromyography Kinesiology 5:197-226.

McGill, S.M. 1991. Electromyographic activity of the abdominal and low back musculature during the generation of isometric and dynamic axial trunk torque: Implications for lumbar mechanic. J. Orthopaedic Res. 9:91-103.

McGill, S.M. and R.W. Norman. 1986. Partitioning of the L4/L5 dynamic moment into disc, ligamentous, and muscular components during lifting. Spine 11:666-678.

Morey-Klapsing, G., A. Arampatzis, and G.P. Bruggemann. 2004. Choosing EMG parameters: Comparison of different onset determination algorithms and EMG integrals in a joint stability study. Clinical Biomechanics 19:196-201.

Murphy, M.A., K.S. Sunnerhagen, B. Johnels, and C. Willen. 2006. Three-dimensional kinematic motion analysis of a daily activity drinking from a glass: A pilot study. J. Neuroengineering Rehabiltation 3:18.

Myers, J.B., M.R. Pasquale, K.G. Laudner, T.C. Sell, J.F. Bradley, and S.M. Lephart. 2005. On-the-field resistance-tubing exercises for throwers: An electromyographic analysis. J. Athletic Training 40:15-22.

MyoResearch, X.P. 2011. Master edition/basic edition 1.04. Main manual. Noraxon INC, Scottsdale, AZ.

Ochia, R.S. and P.R. Cavanagh. 2007. Reliability of surface EMG measurements over 12 hours. J. Electromyography Kinesiology 17:365-371.

Page, C., S.I. Backus, and M.W. Lenhoff. 2003. Electromyographic activity in stiff and normal elbows during elbow flexion and extension. J. Hand Therapy 16:5-11.

Park, S.A., A.Y. Lee, K.S. Lee, H.S. Lee, J.E. Song, B.R. Kim, K.S. Lee, K.C. Son, and C.A. Shoemaker. 2012a. Metabolic equivalents of gardening tasks as a physical activity in children and adults. Kor. J. Hort. Sci. Technol. 30(Suppl. II):181. (Abstr.) 
Park, S.A., C.A. Shoemaker, and M.D. Haub. 2008a. A preliminary investigation on exercise intensities of gardening tasks in older adults. Perceptual Motor Skills 107:974-980.

Park, S.A., C.A. Shoemaker, and M.D. Haub. 2008b. Can older gardeners meet the physical activity recommendation through gardening? HortTechnology 18:639-643.

Park, S.A., C.A. Shoemaker, and M.D. Haub. 2009. Physical and psychological health conditions of older adults classified as gardeners or nongardeners. HortScience 44:206-210.

Park, S.A., H.S. Lee, K.S. Lee, K.C. Son, and C.A. Shoemaker. 2013a. The metabolic costs of gardening tasks in children. HortTechnology 23:589-594.

Park, S.A., K.S. Lee, and K.C. Son. 2011. Determining exercise intensities of gardening tasks as a physical activity using metabolic equivalents in older adults. HortScience 46:1706-1710.

Park, S.A., K.S. Lee, K.C. Son, and C.A. Shoemaker. 2012 b. Metabolic cost of horticulture activities in older adults. J. Jpn. Soc. Hort. Sci. 81:295-299.

Park, S.A., S.R. Oh, K.S. Lee, and K.C. Son. 2013b. Electromyographic analysis of upper limb and hand muscles during horticultural activity motions. HortTechnology 23:51-56.

Restuccio, J.P. 1992. Fitness the dynamic gardening way. Balance of Nature Publ., Cordova, TN.

Soderback, I., M. Soderstrom, and E. Schalander. 2004. Horticultural therapy: The 'healing garden' and gardening in rehabilitation measures at Danderyd Hospital Rehabilitation Clinic, Sweden. Pediatric Rehabilitation 7:245-260.

Stevens, V.K., T.G. Parlevliet, P.L. Coorevits, N.N. Mahieu, K.G. Bouche, G.G. Vanderstraeten, and L.A. Danneels. 2008. The effect of increasing resistance on trunk muscle activity during extension and flexion exercises on training devices. J. Electromyography Kinesiology 18:434-445.

Tsuboi, H., Y. Nishimura, T. Sakata, H. Ohko, H. Tanina, K. Kouda, T. Nakamura, Y. Umezu, and F. Tajima. 2013. Age-related sex differences in erector spinae muscle endurance using surface electromyographic power spectral analysis in healthy humans. Spine J. 13:1928-1933.
Turner, C.H. and A.G. Robling. 2003. Designing exercise regimens to increase bone strength. Exercise Sports Sci. Rev. 31:45-50.

Turner, L.W., M.A. Bass, L. Ting, and B. Brown. 2002. Influence of yard work and weight training on bone mineral density among older U.S. women. J. Women Aging 14:139-148.

Vaiman, M., E. Eviatar, and S. Segal. 2004. Surface electromyography studies of swallowing in normal subjects: A review of 440 adults. Report 2. Quantitative data: Amplitude measures. Otolaryngology Head Neck Surgery 131:773-780.

Vaughan, C.L., B.I. Davis, and J.C. O’Connor. 1992. Dynamics of human gait. Human Kinetics Publishers, Champaign, IL.

van Ingen Schenau, G.J., W.M.M. Dorssers, T.G. Welter, A. Beelen, G. de Groot, and R. Jacobs. 1995. The control of mono-articular muscles in multijoint leg extensions in man. J. Physiol. 484:247-254.

Yang, J.F. and D.A. Winter. 1983. Surface EMG profiles during different walking cadences in humans. Electroencephalography Clinical Neurophysiology 60:485-491.

Yoon, H.K., S.Y. Oh, Y.S. Kim, S.H. Cho, and S.M. Yang. 2006. The EMG analysis on forelimb muscles during a forehand-stroke according to the hit direction of the tennis ball. Korea J. Sports Sci. 15:675-683.

Youdas, J.W., J.H. Hollman, J.R. Hitchcock, G.J. Hoyme, and J.J. Johnsen. 2007. Comparison of hamstring and quadriceps femoris electromyographic activity between men and women during a single-limb squat on both a stable and labile surface. J. Strength Conditioning Res. 21:105-111.

Wang, D. and T. Macmillan. 2013. The benefits of gardening for older adults: A systematic review of the literature. Activities Adaptation Aging 37:153-181.

Woo, S.H. 2013. EMG analysis of major muscles during shooting in archers. MS Thesis, Korea National Sport Univ., Seoul, Korea.

Zeller, B.L., J.L. Mccrory, W.B. Kibler, and T.L. Uhl. 2003. Differences in kinematics and electromyographic activity between men and women during the single-legged squat. Amer. J. Sports Medicine 31:449-456. 